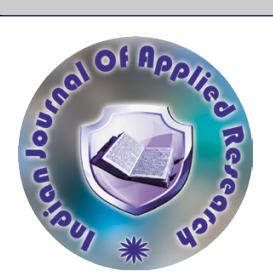

Prosthodontics

\title{
COMPARISON AND EVALUATION OF CLINICAL EXPERIENCE AND GRAPHOANALYSIS USING HOUSE'S CLASSIFICATION, FOR ASSESSMENT OF EMOTIONAL STATUS OF COMPLETELY EDENTULOUS PATIENTS, IN SUCCESS OF COMPLETE DENTURE.
}

Sargam R. Parate*

\section{Dr. Jaishree} Chahande
Intern, Department of Prosthodontics and Implantology, VSPM Dental College and Research Centre, Digdoh hills , Nagpur -440019. *Corresponding Author Lecturer, Department of Prosthodontics and Implantology, VSPM Dental College and Research Centre, Digdoh hills , Nagpur -440019.

Dr. Rahul Gandhi Reader, Department of ODMR, Saraswati Dhanwantari Dental college, Parbhani.

ABSTRACT Aim: To compare and evaluate clinical experience and graphoanalysis, using House's classification in assessing the emotional status of completely edentulous patients in success of complete denture.

Settings And Design: Comparative analytical study.

Methods And Material: 50 completely edentulous patients of age above 45 years (M/F) were taken as subjects. Literate patients were included in the study while incompetent patients and illiterate patients were excluded. Patients were asked to express their expectations regarding the treatment on paper in their handwritings using vernacular language. Subjects were categorized on the basis of age and gender. The handwriting samples were collected and graphoanalysis was done.

Statistical Analysis Used: The resultant data was subjected to statistical analysis using chi square test and spearman's rank correlation test.

Results: Considering age, on graphoanalysis (P-18, I-14, E-14, H-4) were found, when compared to Clinical experience (P-23, I-12, E-13, H2). While considering gender, on GA (P-18, I-14, E-14 and H-4) were found when compared to CE (P-23, I-12, E-13 and H-2). Chi-square test showed CE and GA were independent of age and gender. Spearman's rank correlation between CE and GA was 0.217.

Conclusions: Clinical experience and graphoanalysis of complete denture patient are independent of Age and Gender. There was a significant correlation between $\mathrm{CE}$ and GA, so graphoanalysis can be used for ascertaining the mental attitude of completely edentulous patient.

\section{KEYWORDS : Completely edentulous patients, Clinical experience (CE), Graphoanalysis (GA) Philosophical (P), Indifferent} (I), Exacting (E), and Hysterical $(\mathrm{H})$.

\section{INTRODUCTION:}

Smile and satisfaction brings quality to life. This is achieved by complete denture in an edentulous person, which helps in avoiding disturbances in speech, aesthetics, mastication and inferiority. Satisfaction is an outcome of clinical excellence which is obtained by communication, empathy and human connection. ${ }^{[1-4]}$

The success of complete denture, comprises not only clinical work but it deals with biological, physiological, social, and economical and most importantly psychological status of the patient. Studies have shown that patient's mental attitude plays a vital role in treatment planning and even can be the factor leading to failure of complete denture. $^{[5-8]}$

Thus, it becomes important for prosthodontist to gain knowledge regarding emotional level of patient, which would help in rectifying the frequency and intensity of problems, understand, empathize patients conditions, thereafter providing better dental treatment to the patient. ${ }^{[9-10]}$

Many researches, have been taken place for evaluating mental attitude of complete denture patients, which included interviews, questionnaire, psychological tests, generalised classification by M.M. House. The newer methods which have been used are handwritings, signatures and finger prints too.

Handwriting is brain writing, which reveals current status of the person. Handwriting analysis has been a valid and reliable indicator of personality, thus avoiding an unstructured vague stimuli (interviews).

${ }^{22}$ Therefore examination of different elements and interpretation of handwriting would help in evaluating the patients' mental attitude leading to meet patient's expectations from the treatment. With this background a clinical study was designed to evaluate the effectiveness of graphoanalysis in assessing the emotional status of completely edentulous patients in success of complete denture.

\section{Subjects and Methods:}

A cross-sectional study was taken place, including 50 completely edentulous patient. The study is designed to compare and evaluate the effectiveness of clinical experience and graphoanalysis, therefore it included the following criteria:

\section{Inclusion Criteria:}

- Age: 45 \& above.
- Gender: Male and Female

- Completely edentulous patients with or without prior denture wearing experience.

- Literate patients.

Exclusion Criteria:

- Patients having root pieces.

- Medically compromised patients.

- Illiterate patients.

The patients were verbally explained about the study. They were asked to express, about their expectations and queries regarding the treatment and denture on a plain paper in their handwritings. Subjects were asked to write in their vernacular languages (Hindi and Marathi) to obtain genuine results. The patients were randomly selected and coded to eliminate the selection bias. During same appointment routine case history was taken and oral examination were done by an investigator. The handwriting samples and case history were taken separately, also the investigator were totally blinded throughout the study. The patients were, evaluated and categorized based on clinical experience during treatment according to classification of mental attitude given by M.M .House ${ }^{[13-14]}$ M.M.House classified patients into four psychological types as follows-

1. Philosophical - Philosophical patients are rational and composed in difficult situations. They have the best mental attitude for acceptance of the treatment. They desire treatment for maintenance of health and appearance and accept the complete denture treatment as a normal procedure.

2. Indifferent - Indifferent patients are identified by the lack of concern and motivation towards the treatment. They may not pay attention to instructions, may not corporate and are prone to blame others including the dentist for their poor health.

3. Exacting- Exacting patients are very methodical, precise and accurate in making severe demands. These patients are comfortable when each procedure is explained and discussed with them in detail, while requires extreme care, effort and patience on the part of the dentist.

4. Hysterical - Hysterical patients are more emotionally unstable, excitable and apprehensive about having dental treatment. These patients are more convinced that they will never be able to wear denture. They cannot accept any responsibility for any dental problems. An additional psychiatric counselling is required prior to the treatment for these patients. Subjects were categorized for data 
Volume - 10 | Issue - 10 | October - 2020 | PRINT ISSN No. 2249 - 555X | DOI : 10.36106/ijar processing as,

1. On the basis of AGE :

- 45-55 Years

- 55-65 years

- 65-75 years

- 75 and above years

\section{On the basis of GENDER :}

- Male

- Female

The handwriting samples were submitted for graphoanalysis. The graphoanalyst was kept unacquainted regarding the details of the patients. The graphoanalyst made use of magnifying glass, and evaluated the handwriting of every patient by assessing general and individual characteristics. The general characteristic include alignment, size, shapes, slant and strokes, whereas individual characteristics include placement and formation of modifiers, spacing between words, shape and placement of dot, and placement of letters which were specifically evaluated as shown in following figure $1 .^{[15-17]}$

Observations made in the study were tabulated in Microsoft Excel sheet, while statistical analysis was done using IBM SPSS Version 20 software. Chi-square test was used to evaluate clinical experience with graphoanalysis on the basis of age and gender, while Spearman rank correlation test was used to check the correlation between clinical evaluation and graphoanalysis.

\begin{tabular}{|c|c|c|c|c|}
\hline Characteristics & Philosophical & Indifferent & Exacting & Hysterical \\
\hline Alignment & 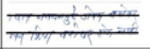 & 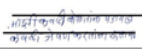 & 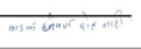 & 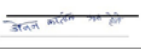 \\
\hline Size & बसेकर & दुखा & usiuci & हो \\
\hline Slant & गदिन & 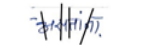 & diftit & \\
\hline Strokes & जेवप & गेवसांना & Aaur & \\
\hline $\begin{array}{l}\text { Spacing between } \\
\text { the words }\end{array}$ & 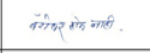 & 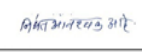 & 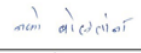 & 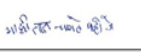 \\
\hline $\begin{array}{l}\text { Shape and type of } \\
\text { dot placed }\end{array}$ & $\dot{p} \sin$ & असतांका. & बोलेक्रिक्ष & कराल \\
\hline
\end{tabular}

\begin{tabular}{|c|c|c|c|c|}
\hline Modifiers & नाही & नंको, & जichl & At+ol \\
\hline Pressure & पहिने & याजजे & wrect & वर्हो जै \\
\hline
\end{tabular}

Figure 1: Comparison Of Psychological Types Using Different Characteristics Of Graphology.

\section{RESULTS:}

The study included 50 completely edentulous patient, of mean age 63.12 and S.D 8.21. The study evaluated effectiveness of graphoanalysis assessing the emotional status of completely edentulous patients, depending upon age and gender of the patient, when compared with clinical experience. On analysis, it was found that maximum patients were philosophical and minimum were hysterical

When evaluation of mental attitude was done, taking into consideration the age of the patient, using Chi-square test [Table 1] it was found that,

- 45-55 years, on clinical experience, patients were more philosophical (6 observed), while on graphoanalysis more exacting ( 5 observed) subjects were observed.

- In 55-65 years, on graphoanalysis more indifferent patients were observed ( 8 observed), when compared with clinical experience (6 observed).

- In 65-75 years, it was observed that on graphoanalysis more exacting patients ( 5 observed) were present, while in clinical experience equal number of indifferent and exacting patients were observed (4 observed each).

- In 75-85 years, on clinical experience and graphoanalysis philosophical patients were more (4 observed and 3 observed respectively). It was found that graphoanalysis is able to encounter hysterical patient ( 1 observed), when compared with clinical evaluation ( 0 observed).

It was observed that more difficult patients were encountered using graphoanalysis (Indifferent -14, Exacting - 14, Hysterical - 4) when compared to clinical experience (Indifferent -12, Exacting -13, Hysterical - 2). Using statistical analysis the calculated value of chisquare is 18.28 where $\mathrm{p}$ - value was set at $0.631>0.05$, which indicated that clinical experience and graphoanalysis of complete denture patient are independent of Age as shown in following graph 1.

Table 1: Representation Of Clinical Experience And Grapho analysis Of Complete Denture Patient Depending Upon Age.

\begin{tabular}{|c|c|c|c|c|c|c|c|c|c|c|}
\hline & & \multicolumn{4}{|c|}{ Clinical Experience } & \multicolumn{4}{|c|}{ Graphoanalysis } & \multirow[b]{2}{*}{ Total } \\
\hline & & \begin{tabular}{|l|} 
Philosophical \\
\end{tabular} & Indifferent & Exacting & Hysterical & Philosophical & Indifferent & Exacting & Hysterical & \\
\hline $44-55$ & Observed Count & 6 & 2 & 3 & 0 & \begin{tabular}{|l|}
3 \\
\end{tabular} & 3 & 5 & 0 & 11 \\
\hline $55-65$ & Observed Count & 10 & 6 & 5 & 2 & 9 & 8 & 3 & 3 & 23 \\
\hline $65-75$ & Observed Count & 3 & 4 & 4 & 0 & 3 & 3 & 5 & 0 & 11 \\
\hline $75-85$ & Observed Count & 4 & 0 & 1 & 0 & 3 & 0 & 1 & 1 & 5 \\
\hline Total & Observed Count & 23 & 12 & 13 & 2 & 18 & 14 & 14 & 4 & 50 \\
\hline
\end{tabular}

\begin{tabular}{|l|l|l|l|l|l|l|l|}
\hline & Value & df & p-value & When evaluation of mental attitude of completely edentulous patient
\end{tabular}

\begin{tabular}{|l|l|l|l|}
\hline Pearson Chi-Square & 18.28 & 21 & p- value \\
\cline { 1 - 2 } $\mathrm{N}$ of Valid Cases & 100 & & \\
\hline
\end{tabular}
p-value $=0.631>0.05$. observed that [Table 2],
- Males:

Representation of total clinical experience and graphoanalysis of complete denture patient depending upon Age.

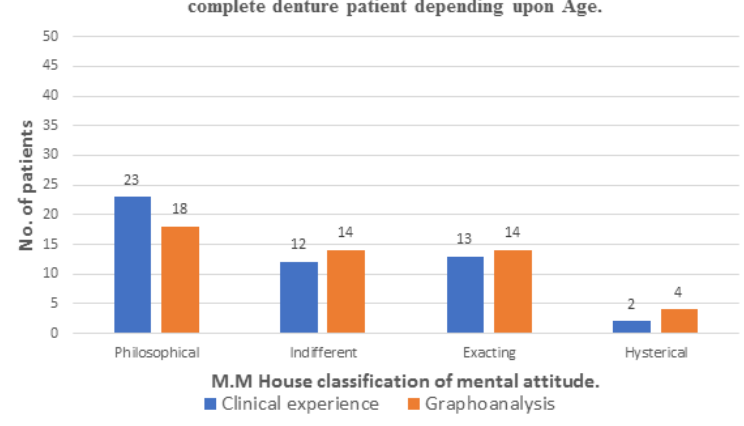

Graph 1: Representation Of Total Clinical Experience And Graphoanalysis Of Complete Denture Patient Depending Upon Age.

Table 2: Representation Of Total Clinical Experience And Graphoanalysis Of Complete Denture Patient Depending Upon Age.

\begin{tabular}{|c|c|c|c|c|c|c|c|c|c|c|}
\hline \multicolumn{2}{|c|}{ Gender } & \multicolumn{4}{|c|}{ Clinical Experience } & \multicolumn{4}{|c|}{ Graphoanalysis } & \multirow[b]{2}{*}{ Total } \\
\hline & & \begin{tabular}{|l|} 
Philosophical \\
\end{tabular} & Indifferent & Exacting & Hysterical & \begin{tabular}{|l} 
Philosophical \\
\end{tabular} & Indifferent & Exacting & Hysterical & \\
\hline $\mathrm{M}$ & Observed Count & 8 & \begin{tabular}{|l|l|}
7 & \\
\end{tabular} & 5 & 0 & 8 & 4 & 6 & 2 & 40 \\
\hline $\mathrm{F}$ & Observed Count & 15 & 5 & 8 & 2 & 10 & 10 & 8 & 2 & 60 \\
\hline
\end{tabular}

1. Clinical experience: Philosophical (8 observed), Indifferent (7observed), Exacting (5 observed) and Hysterical ( 0 observed).

2. Graphoanalysis: Philosophical (8 observed), Indifferent (4 observed), Exacting (6 observed) and Hysterical (2 observed).

\section{- Females:}

1. Clinical experience: Philosophical (15 observed), Indifferent (5 observed), Exacting (8 observed), Hysterical (2 observed).

2. Graphoanalysis: Philosophical (10 observed), Indifferent (10 observed), Exacting (8 observed) and Hysterical (2 observed).

On graphoanalysis more (Indifferent-14, Exacting-14 and Hysterical4) were encountered when compared to clinical experience, (Indifferent-12, Exacting-13 and Hysterical-2) as shown in following graph 2. Therefore, graphoanalysis is able to encounter more difficult patients, but by using statistical analysis the calculated value of chisquare is 4.412 , where $p$-value was set at $0.731>0.05$, it indicated that clinical experience and graphoanalysis of complete denture patient independent on gender. 
Volume - $10 \mid$ Issue - 10 | October - 2020 | PRINT ISSN No. 2249 - 555X | DOI : 10.36106/ijar

\begin{tabular}{|l|l|l|l|l|}
\hline \hline Total & 23 & 12 & 13 & 2 \\
\hline \hline Chi-Square Tests & Value & df & Asymp. Sig. (2-sided) \\
\hline \multicolumn{2}{|l|}{ Pearson Chi-Square } & $4.412^{\mathrm{a}}$ & 7 & 0.731 \\
\hline
\end{tabular}

\section{$\mathrm{p}$-value $=0.731>0.05$.}

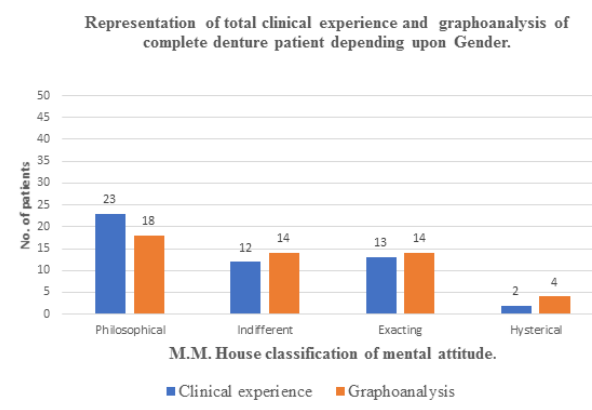

Graph 2: Representation Of Total Clinical Experience And Graphoanalysis Of Complete Denture Patient Depending Upon Gender.

The Spearman's rank correlation between Clinical Experience and Graphoanalysis came out to be 0.217 , where the correlation is significant at 0.05 . This indicated that, there is significant correlation between clinical experience and graphoanalysis as shown in following [Table 3].

Table 3: Spearman's Rank Correlation Between Clinical Experience And Graphoanalysis.

\begin{tabular}{|l|l|l|l|l|}
\hline \multicolumn{3}{|c|}{} & $\mathrm{C}$ & $\mathrm{G}$ \\
\hline Spearman's rho & CE & Correlation Coefficient & 1.000 & $.217^{*}$ \\
\cline { 3 - 4 } & & Sig. (2-tailed) &. & .030 \\
\cline { 3 - 4 } & $\mathrm{N}$ & 100 & 100 \\
\cline { 2 - 4 } & GA & Correlation Coefficient & $.217^{*}$ & 1.000 \\
\cline { 3 - 4 } & Sig. (2-tailed) & .030 &. \\
\cline { 2 - 4 } & $\mathrm{N}$ & 100 & 100 \\
\hline
\end{tabular}

\section{DISCUSSION:}

Graphoanalysis is considered as pseudoscience. It is self-validating and has been ranked second, immediately after interview with $93 \%$ of frequency in evaluating the mental status of an individual. ${ }^{[18]}$ It is a scientific interpretation of mental activity and act as indicator of emotional liability. Thorough history of literature, reveals that graphoanalysis can be used in evaluation of completely edentulous patient, as done by Potgeiter ${ }^{[19]}$ and Nassif. ${ }^{[20]}$

The use of M.M.House classification of emotional status has been strongly appreciated by Nassif earlier and has also been used recently by the many researchers. Literature states that House's classification is extensive in clinical experience and has stood up well for longer period of time ${ }^{[21]}$. hence it was also employed in present study.

As handwriting reveals the true personality of the person, therefore in the present study, handwriting samples of the completely edentulous patient in their vernacular language were included to obtain genuine results.

In the study conducted by Shweta Choudhary et al, the correlation of patients' mental attitude was done by using questionnaire, where as in the present study, clinical experience and graphoanalysis was used for the same ${ }^{[2]]}$ The study revealed the correlation depending upon age, gender and educational status, while the present study too included age and gender excluding educational status and concluded that the clinical experience and Graphoanalysis were independent of age and gender.

A study by Varsha Murthy ${ }^{[0]}$, revealed identification of difficult patients (indifferent, exacting, and hysterical) was more by Graphoanalysis, similarly the present study, is also capable of proving the same.

In the present study after statistical analysis we found that use of graphoanalysis in identifying difficult patients like exacting and hysterical were more than clinical experience. Understanding of patients' perceptions, is the key to the successful treatment of completely edentulous patient. Thus, to obtain the same the present study has made efforts in attempting to analyse the emotional status in a simpler and innovative way.

\begin{tabular}{|l|l|l|}
\hline 14 & 4 & 100 \\
\hline
\end{tabular}

\section{Limitations:}

Clinical experience and Graphoanalysis being independent of age and gender could be due to the smaller sample size. Smaller sample size of 50 patients, was taken as the study was conducted during clinical posting. Graphoanalysis could also have some limitations as, it is not applicable to illiterate patients, also as the handwritings may get changed with time, this could misguide the operator for future predictions of emotional status.

\section{Clinical Significance:}

Dentist could evaluate the mental attitude of patient, depending upon the graphology by taking demographic details of the patients in their handwriting. Graphoanalysis is a predictable science, which can be used by dentist routinely. Gaining knowledge regarding emotional level of patient, would help to understand and empathize patient's conditions, thereafter providing better dental treatment to the patient.

\section{CONCLUSION:}

Graphoanalysis and clinical experience are independent of age and gender since, graphoanalysis could identify difficult patients, it can be used in evaluation of mental status of completely edentulous patients independently, as it has significant correlation with clinical experience. Newer studies can be conducted in future by inculcating bigger sample size and including different methods for evaluating the mental attitude of completely edentulous patients.

\section{Acknowledgements:}

I acknowledge and thank Dr. Mrs. Sandhya Dhabe for putting her contribution into statistics of the study.

Source(s) Of Support: The present study was self-funded.

Conflicting Interest: There are no conflicts of interest.

\section{REFERENCES:}

1. Baer ML, Elias SA, Reynolds MA. The use of psychological measures in predicting patient satisfaction with complete dentures. International Journal of Prosthodontics. 1992 May $1 ; 5(3)$.

2. Langer A, Michman J, Seifert I. Factors influencing satisfaction with complete dentures in geriatric patients. Journal of Prosthetic Dentistry. 1961 Nov 1;11(6):1019-31,

3. Friedman N, Landesman HM, Wexler M. The influences of fear, anxiety, and depression on the patient's adaptive responses to complete dentures. Part I. The Journal of prosthetic on the patient's adaptive responses
dentistry. 1987 Dec 1;58(6):687-9.

4. Heartwell Jr CM. Psychologic considerations in complete denture prosthodontics. The Journal of prosthetic dentistry. 1970 Jul 1;24(1):5-10.

5. Singh S, Mishra SK, Chowdhary R. Patient expectations and satisfaction with conventional complete dentures: a systematic review. Tanta Dental Journal. $2019 \mathrm{Apr}$ $1 ; 16(2): 55$.

6. Sanketh AK, Sridevi J, Kalavathy N, Shetty MM, Kumar R, Pavan TP. A survey of the prosthetic status and post treatment satisfaction of patients among a South Indian population. SRM Journal of Research in Dental Sciences. 2016 Jan 1;7(1):17.

7. Bandodkar KA, Aras M. Psychological considerations for complete denture patients. The Journal of Indian Prosthodontic Society. 2007 Apr 1;7(2):71.

8. Fouda SM, Al-Attar MS, Virtanen JI, Raustia A. Effect of patient's personality on Fouda SM, Al-Attar MS, Virtanen J, Raustia A. Effect of patient's personality on
satisfaction with their present complete denture and after increasing the occlusal vertical dimension: a study of edentulous egyptian patients. International journal of dentistry. 2014 Jan 1;2014.

9. Murthy JV, Singh S, Shakila R, Shastri M. Comparison of Graphoanalysis with House Method in Prediction of Complete Denture Patient's Mental Attitude: A Prospective Comparative Study. The Journal of Indian Prosthodontic Society. 2013 Mar 1;13(1):24-9.

10. Sondell K, Söderfeldt B. Dentist-patient communication: a review of relevant models. Acta Odontologica Scandinavica. 1997 Jan 1;55(2):116-26.

11. Grewal PK, Prashar D. Behavior prediction through handwriting analysis. IJCST. 2012 Apr;3(2):520-3.

12. Varshney A, Puri S. A survey on human personality identification on the basis of handwriting using ANN. In2017 international conference on inventive systems and control(ICISC) 2017 Jan 19 (pp. 1-6). IEEE.

13. Winkler S. House mental classification system of denture patients: The contribution of Milus M. House. Journal of Oral Implantology. 2005 Dec 1;31(6):301-3.

14. Goodacre CJ, Naylor WP. Evolution of the Temperament Theory and Mental Attitude in Complete Denture Prosthodontics: From Hippocrates to MM House. Journal of Prosthodontics. 2020 Jun 19.

15. Sorate P, Kanwal NK, Malhotra M. Comparison of various writing characteristics of Hindiand Marathi languages of Devanagari origin.

16. Pawar VR, Gaikwad A. Multistage Recognition Approach for Offline Handwritten Marathi Script Recognition. International Journal of Signal Processing, Image Processing and Pattern Recognition. 2014;7(1):365-78.

17. Saoji R, Mohod SW, Nikose MC. Design and Implementation Recognition System for Handwritten Hindi/Marathi Document. International Journal on Recent and Innovation Trends in Computing and Communication.;5(7):369-73.

18. Dazzi C, Pedrabissi L. Graphology and personality: an empirical study on validity of handwriting analysis. Psychological reports. 2009 Dec;105(3_suppl):1255-68.

19. Potgieter PJ, Carey PD. The use of graphoanalysis for complete denture patient Potgieter PJ, Carey PD. The use of graphoanalysis for comple
evaluation. Journal of Prosthetic Dentistry. 1983 Nov 1;50(5):623-6.

20. Nassif J. A self-administered questionnaire - An aid in managing complete denture patients. The Journal of Prosthetic Dentistry. 1978 Oct 1;40(4):363-6.

21. Choudhary S, Kumar A, Arora H. Correlation of patient's mental attitude with age, sex, and educational level: A survey. European journal of dentistry. 2016 Jan;10(1):23. 